\title{
Влияние хондропротективной терапии на силовые характеристики околосуставных мышц спортсменов с посттравматической хондропатией коленных суставов
}

\author{
'Н. В.Капустина, ${ }^{2}$ Е. Н.Запольнова \\ ${ }^{1}$ Российский государственный университет физической культуры, спорта, \\ молодежи и туризма, Москва, Россия \\ ²Российский университет Дружбы народов, Москва, Россия
}

\begin{abstract}
Резюме. Представлено результати дослідження ефективності лікування спортсменів із посттравматичною хондропатією колінних суглобів із застосуванням хондропротекторів (хондроїтин-сульфату). Виявлено велику ефективність лікування у комплексі з хондропротективною терапією, що підтверджено даними динаміки параметрів питальника KOOS і динамікою силових характеристик показників ізокінетичного тестування парартикулярних м'язів колінних суглобів.
\end{abstract}

Ключові слова: спортсмен, посттравматична хондропатія, колінний суглоб, KOOS, хондроїтин-сульфат, Biodex System 4 Pro.

Summary. The article presents the research results on effectiveness of cartilage protectors (chondroitin sulfate) use in comprehensive medical rehabilitation of athletes with posttraumatic knee joint chondropathy. High efficiency of treatment combined with chondroprotective therapy was detected according to change in KOOS questionnaire parameters. We detected the decrease in strength of paraarticular muscles of the damaged knee joint based on the data of isokinetic testing compared to the contralateral extremity.

Key words: posttraumatic chondropathy, knee joint, KOOS, chondroitin sulfate, Biodex System 4 Pro.

Введение. Посттравматическая хондропатия - медленно протекающий дегенеративнодистрофический процесс в гиалиновом хряще коленного сустава. Травма вызывает патологические изменения суставного хряща в виде нарушения его структуры, истончения и разволокнения $[3,5,9]$. Кроме того она является пусковым механизмом развития вторичного (посттравматического) гонартроза у спортсменов - осложнения, которые встречаются в 35,5-69,75 \% случаев, и развивается в среднем через три-пять лет после травмы [2, 10, 12].

Посттравматическая хондропатия коленных суставов вызывает снижение силовых характеристик околосуставных мышц и влечет за собой развитие артроза коленного сустава $[4,8]$.

Восстановительное лечение спортсменов с такой патологией требует выполнения широчайшего комплекса профилактических и реабилитационных мероприятий, которые должны включать как медикаментозную терапию, так и немедикаментозные методы лечения.

Важным направлением в профилактике вторичного гонартроза и комплексном лечении спортсменов с медленно протекающими посттравматическими дегенеративными процессами в коленном суставе является хондропротективная терапия. Типичный представитель данной группы препаратов - хондроитин-сульфат. Многочисленными клиническими испытаниями доказано симптом-модифицирующее и структурно-модифицирующее действие хондроитинсульфата на течение заболевания [11]. Метод восстановительного лечения спортсменов с посттравматической хондропатией коленных суставов с применением хондроитин-сульфрата представляет особый интерес в спортивной медицине.

Цель исследования - оценить в сравнительном аспекте влияние хондроитин-сульфрата (Артрадола) на силовые характеристики мышц разгибателей голени у спортсменов с посттравматической хондропатией коленного сустава.

Материалы и методы исследования. В исследовании приняли участие 60 спортсменов игровых видов спорта (футбола, гандбола, волейбола) разной спортивной квалификации (от I разряда до МСМК) с посттравматической 
ТАБЛИЦА 1 - Динамика показателей шкалы KOOS (n = 30, $\overline{\mathbf{X}} \pm \sigma$ )

\begin{tabular}{|l|c|c|c|c|c|c|}
\hline \multirow{2}{*}{\multicolumn{1}{|c|}{ Показатель }} & \multicolumn{3}{|c|}{ Основная группа } & \multicolumn{3}{c|}{ Группа сравнения } \\
\cline { 2 - 7 } & Визит 1 & Визит 3 & Визит 4 & Визит 1 & Визит 3 & Визит 4 \\
\hline Боль & $75,6 \pm 12,9$ & $79 \pm 11,2$ & $84,3 \pm 10$ & $75,0 \pm 20$ & $79,5 \pm 14,2$ & $75,8 \pm 12,7$ \\
\hline Симптомы & $54,4 \pm 8,1$ & $61,9 \pm 10,7$ & $69,7 \pm 10,1$ & $54,9 \pm 13,9$ & $60,1 \pm 13,8$ & $57,7 \pm 7,9$ \\
\hline Ежедневная активность & $83,3 \pm 12,4$ & $84,4 \pm 11,3$ & $86,9 \pm 9,7$ & $85,4 \pm 18$ & $87,8 \pm 10,4$ & $86,9 \pm 10,2$ \\
\hline Спортивная активность & $61,2 \pm 19,7$ & $67,1 \pm 15,9$ & $78,1 \pm 13,7$ & $58,2 \pm 14,7$ & $66,3 \pm 11,8$ & $57,3 \pm 13,6$ \\
\hline Качество жизни & $62,9 \pm 18,1$ & $69 \pm 14$ & $78,9 \pm 11,3$ & $61,9 \pm 18,2$ & $67,7 \pm 13,1$ & $64,7 \pm 12,9$ \\
\hline Итоговый индекс & $71,9 \pm 15,9$ & $76 \pm 10,2$ & $81,7 \pm 9$ & $72,6 \pm 15,4$ & $77 \pm 8,7$ & $73,9 \pm 8,3$ \\
\hline
\end{tabular}

хондропатией. Средний возраст спортсменов $25,8 \pm 7,2$ лет. Стаж занятий спортом - $12 \pm 4$ года.

Bce спортсмены были разделены на две группы, сопоставимые по полу, возрасту и степени структурных изменений в травмированных коленных суставах. Спортсмены основной группы $(\mathrm{n}=30)$ прошли курс лечения препаратом Артрадол (внутримышечно 30 инъекций через день, согласно инструкции производителя), группа сравнения ( $n=30)$ - курс магнитотерапии.

Для изучения субъективной оценки функционального состояния поврежденного коленного сустава использовали шкалу оценки исхода повреждений и заболеваний коленного сустава KOOS (Knee injury and osteoarthritis outcome score [7]. Шкала состоит из пяти подразделов: боль; симптомы; сложность выполнения ежедневных бытовых действий; спорт; активность на отдыхе; качество жизни. В соответствии с цисрровым значением от 0 до 4 подсчитывали количество полученных баллов. Затем с помощью формул производили нормализацию показателей с учетом максимальных значений по каждой субшкале в отдельности и вычисление итогового индекса в целом. Оценка показателя: наилучшая ситуация (отсутствие признака) - значение стремится к 100, наихудшая (максимальная степень выраженности признака) - значение стремится к 0.

С целью объективной оценки функционального состояния коленных суставов у спортсменов

ТАБЛИЦА 2 - Значения показателей субшкал KOOS в исследуемых группах $(\mathrm{n}=30, \overline{\mathrm{X}} \pm \sigma)$

\begin{tabular}{|c|c|c|c|}
\hline Опросник & $\begin{array}{l}\text { Основная } \\
\text { группа }\end{array}$ & $\begin{array}{c}\text { Группа } \\
\text { сравнения }\end{array}$ & $\begin{array}{c}\mathrm{t}-\text { статистика } \\
\left(\mathrm{P}=0,95, \mathrm{t}_{\mathrm{rp}-} 2,04\right)\end{array}$ \\
\hline Визит 1 & $71,9 \pm 15,9$ & $72,6 \pm 5,970$ & 0,2 \\
\hline Визит 3 & $76 \pm 10,2$ & $77 \pm 8,7$ & 0,4 \\
\hline Визит 4 & $81,7 \pm 9$ & $73,9 \pm 8,3$ & 2,2 \\
\hline
\end{tabular}

Примечание. Шрифтом выделены статистически достоверные различия. с посттравматической хондропатией применяли метод изокинетической динамометрии мышцсгибателей и разгибателей голени с применением системы Biodex System 4 Pro (США). Исследование выполнялось по следующему протоколу: режим работы - изокинетический, тестирование двустороннее на угловых скоростях - $60,180,300^{\circ}$, количество повторений 5, 10 и 15 соответственно. Для универсальной оценки использовали соотношение пикового вращающего момента к весу тела (ПВМ/ВТ). Сравнительную оценку полученных результатов динамометрии проводили с аналогичными показателями интактной конечности [1]. Критерии оценки: дефицит 1-10 \% - незначительный, коррекция не требуется; 11-25\% - умеренные отклонения, рекомендована реабилитация для улучшения мышечного баланса, > $25 \%$ - значительные функциональные нарушения, требуется активное лечение.

Статистическую обработку и оценку достоверности различий осуществляли вычислением t-критерия Стьюдента.

Результаты исследования и их обсуждение. В течение исследования спортсменам было предложено трижды заполнить опросник: первый опрос (визит 1) - перед началом курса лечения, второй (визит 3) - после окончания лечения, третий опрос (визит 4) - по истечению периода наблюдения (через три месяца после окончания лечения).

Значения показателей субшкал в отдельности и итоговый индекс шкалы KOOS отражены в таблице 1.

Нами была проведена межгрупповая сравнительная оценка эфрфективности курса лечения Артрадолом и магнитотерапией по данным опросника KOOS (табл. 2).

Как видно из таблицы 2, различия значений итогового индекса KOOS между исследуемыми группами до начала лечения и по окончании статистически недостоверны $\left(t<t_{\text {гр }}=2,04\right)$. Однако по окончании периода наблюдения отмечается 
дальнейшее увеличение итогового индекса в основной группе и снижение его в группе сравнения (81,7 \pm 9 и 73,9 \pm 8,3 соответственно). Различия итоговых значений являются статистически достоверными $\left(t>t_{\text {гр }}=2,04\right)$.

Результаты тестирования силовых возможностей мышц-разгибателей голени у спортсменов с посттравматической хондропатией коленного сустава до и после лечения представлены в таблице 3.

Сравнительный анализ силовых характеристик мышц-разгибателей голени показал асимметрию их силы в поврежденной и интактной конечностях на всех угловых скоростях: среднее значение дефицита силы разгибателей голени в обеих группах на скоростях 60, 180 и 300 град $\cdot \mathrm{c}^{-1}$ составляло 18, 13 и $7 \%$ соответственно. После лечения в основной группе выявлено уменьшение дефицита силы тестируемой группы мышц - 14, 10 и 7 \% соответственно.

Результаты статистической обработки и достоверность силовых различий мышц-разгибателей голени в исследуемых группах до и после лечения отражены в таблице 4.

Таким образом, в результате повторного изокинетического тестирования нами выявлено положительное влияние лечения Артрадолом на силовые характеристики околосуставных мышц поврежденного коленного сустава, что проявляется в достоверном уменьшении дефицита силы разгибателей коленного сустава между поврежденной и интактной конечностью на угловых скоростях 60 и $180^{\circ}\left(t>t_{\text {гр }}=2,04\right)$. Изменение

\section{Литература}

1. АлексееВа Л. И. Факторы риска при остеоартрозе // Научно-практ. ревматология. - 2000. - № 2. - С.3645.

2. Арьков В. В. Показатели изокинетической динамометрии мышц бедра у спортсменов после реконструкции передней крестообразной связки коленного сустава / В. В. Арьков, О. Н. Миленин, З. Г. Орджоникидзе // Лечебная фризкультура и спортивная медицина. - 2011. N 12 (96). - C.23-26.

3. Buckwalter J. A. Articular cartilage: degeneration and osteoarthritis, repair, regeneration, and transplantation / J. A. Buckwalter, H. J. Mankin // Instr. Course. Lect. 1998. - Vol. 4, № 7. - P. 487-504.
(\%) мышц-разгибателей голени у спортсменов с посттравматической хондропатией коленных суставов до лечения $(n=30, \bar{X} \pm \sigma)$

\begin{tabular}{|l|c|c|c|c|}
\hline \multirow{2}{*}{$\begin{array}{c}\text { Угловая } \\
\text { скорость, } \\
\text { град } \mathbf{c}^{-1}\end{array}$} & $\begin{array}{c}\text { Поврежденная } \\
\text { мышца }\end{array}$ & $\begin{array}{c}\text { Интактная } \\
\text { мышца }\end{array}$ & $\begin{array}{c}\text { Поврежденная } \\
\text { мышца }\end{array}$ & $\begin{array}{c}\text { Интактная } \\
\text { мышца }\end{array}$ \\
\cline { 2 - 5 } & \multicolumn{4}{|c|}{ До лечения } \\
\hline 60 & $177 \pm 41,3$ & $216,4 \pm 53,2$ & $182,6 \pm 45,1$ & $224,7 \pm 56,5$ \\
\hline 180 & $119,5 \pm 43,9$ & $137,3 \pm 50,9$ & $127,4 \pm 37,9$ & $146,6 \pm 43,3$ \\
\hline 300 & $80,6 \pm 34,8$ & $86,7 \pm 37,1$ & $92,2 \pm 31,3$ & $100,1 \pm 33,8$ \\
\hline \multicolumn{5}{|c|}{ После лечения } \\
\hline 60 & $184,4 \pm 41,2$ & $215 \pm 47,4$ & $183,2 \pm 45,4$ & $222,7 \pm 53,5$ \\
\hline 180 & $122,4 \pm 45,6$ & $136,7 \pm 48,5$ & $127,8 \pm 37,7$ & $146,3 \pm 41,5$ \\
\hline 300 & $80,9 \pm 34,6$ & $86,7 \pm 36,8$ & $92,6 \pm 32,5$ & $100,2 \pm 35,7$ \\
\hline
\end{tabular}

ТАБЛИЦА 4 - Изменение дефицита силовых возможностей мышц-

\begin{tabular}{|c|c|c|c|c|c|c|}
\hline \multirow{2}{*}{$\begin{array}{c}\text { Угловая } \\
\text { скорость, } \\
\text { град } \text { c }^{-1} \\
\end{array}$} & \multicolumn{2}{|c|}{ Основная группа, \% } & \multirow{2}{*}{$\begin{array}{c}\text { t-статистика } \\
(P=0,95 \\
\left.t_{r^{*}}-2,04\right) \\
\end{array}$} & \multicolumn{2}{|c|}{ Группа сравнения, \% } & \multirow{2}{*}{$\begin{array}{c}\text { t-статистика } \\
(P=0,95 \\
\left.t_{r p^{*}}-2,04\right) \\
\end{array}$} \\
\hline & 1 & 2 & & 1 & 2 & \\
\hline 60 & $18,1 \pm 2$ & $14,5 \pm 2,5$ & 6,2 & $18,7 \pm 1,8$ & $18,4 \pm 2,4$ & 0,6 \\
\hline 180 & $12,8 \pm 2,6$ & $10,3 \pm 2,6$ & 3,6 & $13,1 \pm 2,9$ & $12,6 \pm 1,9$ & 0,8 \\
\hline 300 & $7,2 \pm 3,6$ & $6,6 \pm 3,1$ & 0,7 & $7,8 \pm 3,9$ & $7,6 \pm 3,4$ & 0,2 \\
\hline
\end{tabular}

Примечание. Шрифтом выделены статистически достоверные различия

дефицита силы на угловой скорости $300^{\circ}$ недостоверно $\left(t<t_{\text {гр }}=2,04\right)$.

Выводы. В результате проведенного двустороннего изокинетического тестирования мышцразгибателей коленного устава нами выявлено улучшение биомеханических характеристик околосуставных мышц, что проявляется уменьшением асимметрии силы четырехглавой мышцы между поврежденной и интактной конечностями. По нашему мнению, это влияние является косвенным и связано с симптоммодифицирующим действием препарата Артрадол, проявляющимся в уменьшении болевого синдрома, что, в свою очередь, позволяет спортсмену развивать максимальную силу.

\section{References}

1. Alexeeva L. I. Risk factors in ostheoarthrosis / L. I. Alexeeva // Scientific and Practical Rheumatology. 2000. - N 2. - P.36-45.

2. Arykov V. V. Parameters of isokinetic dynamometry of thigh muscles for athletes after reconstruction of knee anterior crucial ligament of joint/ V. V. Arykov, O. N. Milenin, Z. G. Ordzhonikidze // Therapeutic Physical Culture and Sports Medicine. - 2011. - N.12 (96). P. 23-26.

3. Buckwalter J. A.. Articular cartilage: degeneration and osteoarthritis, repair, regeneration, and transplantation / J. A. Buckwalter, H. J. Mankin // Instr. Course. Lect. 1998.- Vol. 4, N 7. - P. 487-504. 
4. Brandt K. D. Is a strong quadriceps muscle bad for a patient with knee osteoarthritis? Text. / K. D. Brandt // Ann. Intern. Med. 2003. - Vol. 138. - P. 678-679.

5. Hunziker E. B. Articular cartilage repair: basic science and clinical progress. A review of the current status and prospects // E. B. Hunziker // Osteoarthritis Cartilage. 2002.- N 10. - P.1432-1463.

6. Hurley M.V. Improvements in quadriceps sensorimotor function and disability of patients with knee osteoarthritis following a clinically practicable exercise regime Text. / M. V. Hurley, D. L. Scott // Brit J. of Rheum. 1998. Vol. 37. - P. 1181-1187.

7. Knee injury and osteoarthritis outcome score (KOOS) development of a self-administered outcome measure/ [E. M. Roos et al.] // J. Orthop. Sports Phys. Ther. 1998. Vol. 28. - P. 88-96.

8. Lewek M. D. Quadriceps femoris muscle weakness and activation failure in patients with symptomatic knee osteoarthritis Text. / M. D. Lewek, K. S. Rudolph, L. SnyderMackler // J. Orthop. Res. 2004. - Vol. 22. - P. 110-115.

9. Martel-Pelletier J. Etiopathogenesis of osteoarthritis / J. Martel-Pelletier, D. Lajeunesse, J. P. Pelletier // Arthritis and Allied Conditions: A Textbook of Rheumatology. W. J. Koopman, L. W. Moreland. Baltimore: lippincott, Wikings W. - 2005. - R. 2199-296.

10. Nie/sen A. B. Epidemiology and traumatolog soccer II / A. B. Nielsen J. Yde // Am. J. Sports Med. - 1989.- 17. P. 803-807.

11. Reachenbach S. Meta-analysis: Chondroitin for osteoarthritis ofthe knee and hip / Reachenbach S., R.Sterchl, M. Scherer et.al. // Ann. Int. Med. - 2007. - N 146. P. $580-590$

12. The Epidemiology, Etiology, Diagnosis, and Treatment of Osteoarthritis of the Knee / [W. P. Michael et al] / / Dtsch. Arztebl. Int. - 2010. - N 107. - P. 152-162.
4. Brandt K. D. Is a strong quadriceps muscle bad for a patient with knee osteoarthritis? Text. / K. D. Brandt // Ann. Intern. Med. 2003. - Vol. 138. - P. 678-679.

5. Hunziker $E$. B. Articular cartilage repair: basic science and clinical progress. A review of the current status and prospects // E. B. Hunziker // Osteoarthritis Cartilage. 2002.- N 10. - P. 1432-1463.

6. Hurley M. V. Improvements in quadriceps sensorimotor function and disability of patients with knee osteoarthritis following a clinically practicable exercise regime Text. / M. V. Hurley, D. L. Scott // Brit J. of Rheum. 1998. Vol. 37. - P. 1181-1187.

7. Knee injury and osteoarthritis outcome score (KOOS) development of a self-administered outcome measure/ [E.M. Roos et al.] / / J. Orthop. Sports Phys. Ther. 1998. Vol. 28. P. 88-96.

8. Lewek M. D. Quadriceps femoris muscle weakness and activation failure in patients with symptomatic knee osteoarthritis Text. / M.D. Lewek, K.S. Rudolph, L. SnyderMackler // J. Orthop. Res. 2004. - Vol. 22. - P. 110-115.

9. Martel-Pelletier J. Etiopathogenesis of osteoarthritis / J. Martel-Pelletier, D. Lajeunesse, J. P. Pelletier // Arthritis and Allied Conditions: A Textbook of Rheumatology. W. J. Koopman, L. W. Moreland. Baltimore: lippincott, Wikings W. - 2005. - R. 2199-296.

10. Nielsen A. B. Epidemiology and traumatolog soccer II / A. B. Nielsen J. Yde // Am. J. Sports Med. - 1989. 17. - P. 803-807.

11. Reachenbach S. Meta-analysis: Chondroitin for osteoarthritis ofthe knee and hip / Reachenbach S., R. Sterchl, M. Scherer et. al. // Ann. Int. Med. - 2007. - N 146. P. $580-590$

12. The Epidemiology, Etiology, Diagnosis, and Treatment of Osteoarthritis of the Knee / [W. P. Michael et al.] / / Dtsch. Arztebl. Int. - 2010. - N 107. - P. 152-162. 